Res Publica. Revista de Historia de las Ideas Políticas ISSN: $1576-4184$

http://dx.doi.org/10.5209/RPUB.57501

\title{
Carne, cuerpo y política: la revolución epicúrea
}

Gustavo Castel de Lucas*

Recibido: 20 de enero de 2017 / Aceptado: 14 de julio de 2017

Resumen. En el presente trabajo tratamos de mostrar el directo y profundo vínculo entre el cuerpo y la política, así en el ámbito del ser como en del deber ser. Inspirándonos en la tradición epicúrea y en el pensamiento del propio Epicuro, intentamos, por un lado, establecer un itinerario político coherente desde el placer humano hasta los fundamentos de la política; por otro, sugerir la utilidad de esa tradición filosófica para pensar la política hoy.

Palabras clave: Epicuro; cuerpo y política; Epicuro y política.

\section{[en] Flesh, Body and Politics: the Epicurean Revolution}

Abstract. In the present work we aim to show the direct and deep link between body and politics both in the is and the ought realms. Using the inspiring Epicurean tradition and the thought of Epicurus himself we try, on the one hand, to establish a coherent political journey from human pleasure to political foundings. On the other hand, we would like to point out the potential of this philosophical tradition to though on politics today.

Keywords: Epicurus; body and politics; Epicurus and politics.

Sumario: 1. Intro: cuerpo y política. Todo es cuerpo. 2. Política y dictado del cuerpo: el cuerpo como domine, la ley del deseo. 3. La revolución epicúrea: contra la Academia y el Liceo. 4. Epicuro: anhelos y desventuras humanos, entre el placer y el dolor. 5. Placer y política. 6. Pacto y placer. 7. Remate.

Cómo citar: Castel de Lucas, G. (2017). Carne, cuerpo y política: la revolución epicúrea, en Res publica 20.3, 561-579.

\section{Intro: cuerpo y política. Todo es cuerpo}

El vínculo entre cuerpo y política, tan visto con la metáfora secular ${ }^{1}$, nos es pretexto perfecto para, con la inspiración de quien fue en el principio, quien volvió a este mundo tocable, corpóreo la esencia de lo real, Epicuro de Samos, usarlo y abusarlo para

\footnotetext{
* Universidad Complutense de Madrid gcastel@wanadoo.es

1 Una síntesis que ilustra bien lo que tantas veces se ha tratado podemos leerla en M. Lacore, "Corps des citoyens, corps de la cité", en Kentron 19, 2003, pp. 1-2.
} 
sostener lo que nos parece raíz en la cuestión de la convivencia humana: el cuerpo es y debe ser principio y fin de la política. Así de sencillo, así de complejo.

No puede dejarse de advertir, antes de infiltrarnos, que cuando de cuerpo(s) hablamos en campo epicúreo, la ruptura doctrinal con gran parte de lo anterior y buena parte de lo posterior es ya radical: como Hobbes siglos después, cuando se retoma con seriedad el pensamiento del maltratado helenista y se funda la modernidad filosófica, científica y política, Epicuro sostuvo que todo es cuerpo ${ }^{2}$. Nada hay que no tenga materia, corporeidad, en suma, pues todo está compuesto de átomos. El delirante sostener la existencia de cuerpos incorpóreos ${ }^{3}$ toca a su fin con todo lo que sustentaba. Y la mofa hobbesiana de la tradición metafísica en ese terreno, bien podría haberla firmado el griego ${ }^{4}$. Como Hobbes firmó, consiguientemente, una de las tesis que más problemas le trajeron: casi dio con su animado cuerpo en la hoguera por afirmar, entre otras cosas, la corporeidad de Dios y el alma. Y es la del alma la que sostuvo Epicuro en términos similares y con insuperable elocuencia ("el alma es un cuerpo"6), para revolcón de todo.

Así pues, el cuerpo del que hablamos, hoy ya, y desde esta perspectiva epicúreo-hobbesiana, incluye lo que antes y después de ambos se designa como alma ${ }^{7}, \mathrm{y}$ muy especialmente el aparato racional de ésta: no nos valdrá, por tanto, la res cogitans cartesiana que trató de demoler el más obvio epicúreo de la modernidad, Gassendi. Hobbes, quien mejor usó la metafísica del de Samos para fines políticos, y gran amigo del provenzal bajo el paraguas de Mersenne, a su vez, emprendió una riquísima polémica con Descartes, con el problema del dualismo como epicentro ${ }^{8}$.

\footnotetext{
"El todo consiste en cuerpos y vacío (...) al margen del todo no hay nada" (Epicuro, Carta a Heródoto, en C. García Gual, Epicuro, Madrid, Alianza, 2006, p. 97). O, en la traducción de Caro y Silva: "no existe nada además del universo que, habiendo ingresado a éste, pudiera producir cambio" (S. Caro y T. Silva, "Epicuro: Epístola a Heródoto"-Introducción, traducción y notas-en Onomázein 17, 2008, pp.135-170, aquí p. 149). No cabe la intervención externa en este mundo corpóreo: presuena claramente el materialismo inmanentista con el que Hobbes y Spinoza revolucionarán el XVII. Eludimos la cuestión del vacío en tanto no es relevante para lo que tratamos de señalar. "For the Universe, being the Aggregate of all Bodies, there is no reall part thereof that is not also Body; nor any thing properly a Body, that is not also part of (that Aggregate of all Bodies) the Universe" (T. Hobbes, Hobbes's Leviathan, reprinted from the edition of 1651, Oxford, Clarendon Press, 1909, p. 302). "The World, (I mean not the Earth onely [...] but the Universe, that is, the whole masse of all things that are) is Corporeall, that is to say, Body (...) Every part of the Universe, is Body; and that which is not Body, is no part of the Universe: And because the Universe is All, that which is no part of it, is Nothing; and consequently no where" (Ibidem, p. 524).

3 Que Hobbes equipara a los fantasmas (Ghost, or incorporeall substance) que, a su vez, quedan asimilados a almas y espíritus, entidades metafísicas o pseudodivinas, a los que por supuesto no ha lugar: "therefore are not Ghosts incorporeall, that is to say, Ghosts that are in no place; that is to say, that are no where; that is to say, that seeming to be somewhat, are nothing" (Ibidem, p. 307). "Substance incorporeall are words, which when they are joined together, destroy one another, as if a man should say, an Incorporeall Body" (Ibidem, p. 303). De haber sido Hobbes latino, su provervial sorna habría resultado más burlona y elocuente que en el original incorporeall bodies, por la raíz que se conserva en el sustantivo.

4 "Los que califican al alma de incorpórea disparatan" (Epicuro, Carta a Heródoto, en C. García Gual, op. cit., p. 107).

5 Hobbes, con habilidad y sutileza, aprovecha los propios pasajes bíblicos para llevar la cosa a su terreno: "if by the Spirit of God be meant God himself, then is Motion attributed to God, and consequently Place, which are intelligible only of Bodies, and not of substances incorporeall" (T. Hobbes, op. cit., p. 304).

6 Epicuro, Carta a Heródoto, en C. García Gual, op. cit., p. 106. Unida a éste, sentiente y viva mientras éste lo esté; cuando perezca, se diseminará con él. Cf. Ibidem, pp. 106-107.

Podríamos decir ahora, mutatis mutandis, "sistema nervioso central".

8 Al respecto, rico también el trabajo de R. Tuck "Hobbes and Descartes", en G. A. J. Rogers y A. Ryan (eds),
} 
Con ese mismo espíritu ${ }^{9}$, preconfigurándolo, quizás la consecuente negación del dualismo platónico que afinará Descartes en el siglo de Hobbes, esa bisustancialidad que define la ontología dominante, resulte la más revolucionaria idea de Epicuro: la que le ganó la proscripción casi para siempre ${ }^{10} \mathrm{y}$ con la que nos trajo a este mundo de piedras y animales todo lo que es y existe. A partir de ahí, por tanto, ética y Derecho, física, fisiología y filosofía, y la política con todo ello, mutarán radicalmente.

Mortal y corpórea ahora el alma platónica, que fue la representante del kosmos noetos, del mundo formal que determinaba el ser y el deber ser en este mundo imperfecto, réplica pobre de aquél, la cosa cambia. La justicia, las leyes, la política eran ajustes a ese modelo. Para Epicuro tal es poco más que mito. Y el cuerpo íntegro, caduco pero cierto, traslocará como base a aquella alma vagante y perenne.

\section{Política y dictado del cuerpo: el cuerpo como domine, la ley del deseo}

Nos parece, por tanto, que ese vínculo entre política y cuerpo es matriz, y no lo decimos con intención metafórica o sociológica: Epicuro coloca al humano en el eje de su vida, al margen de dioses, naturalezas fatales, formas, inteligencias y propósitos transhumanos. Más precisamente, al cuerpo humano, cuerpo que incluye, a todos los efectos, alma. Cuerpo animado ${ }^{11}$ que es, antes que nada, agente y paciente de placer y dolor. A partir de aquí y hasta allí, todo.

El placer es principio y fin del vivir feliz. Pues lo hemos reconocido como bien primero y connatural y de él tomamos el punto de partida en cualquier elección y rechazo y con él concluimos al juzgar todo bien con la sensación como norma y criterio ${ }^{12}$.

"Todo placer (...) es un bien; (...) también cualquier dolor es un mal"13.

Con tal finta a la tradición, que progresará en la historia y el pensamiento, sólo queda una en el campo político: habrá que decidir qué y cómo hacer, en esta adusta tierra, abocándose en primera y última instancia a ese singular cuerpo epicúreo que goza y sufre y piensa sin más amparo que el que él mismo pueda darse.

La idea con la que jugaremos, sobre la base de eso ya dicho, y que por más que pueda sonar frívola en absoluto nos lo parece, como esperamos mostrar, es que en definitiva la primera y última razón de la política, la primera y última causa de la política vienen definidas por lo que nos pide(a) el cuerpo.

Habrá de entenderse que el objeto indirecto, ese nos, pronominaliza a los ciudadanos: pues, por si fuera poco, nos hacemos tales al hacerla y para eso la hacemos. Así, la política es y, sobre todo, debe ser lo que nos pide(a) el cuerpo: el orden descriptivo definirá, en pirueta sencilla, un regimiento normativo determinado por un indeterminado pulso anhelante ${ }^{14}$. Lejos de las trascendencias transmundanas, lejos

\footnotetext{
Perspectives on Thomas Hobbes, Oxford, Clarendon Press, 1988, pp. 11-41.

Válganos el término en este contexto.

Salvada providencialmente por Lucrecio, Laercio o Plutarco, entre otras notabilísimas pero escasas excepciones.

Entidad intencional, pensante: inteligente, razonante.

Epicuro, Carta a Meneceo, en C. García Gual, op. cit., p. 143.

Ibidem.

El que pasiones y razones, propias y comunes, vayan decidiendo.
} 
de órdenes y fines naturales prefijados, lejos de razones desnudas los movimientos de esa materia especialísima que el cuerpo humano es $^{15}$ definen, justifican, planean y edifican el constructo político todo. Parte éste, y acaba, en ellos. La simpleza de la enunciación, obvio, no diluye, no soluciona la complejidad del asunto que abarca. Pero apuntará sendas tangibles y transitables.

Fundar la política sobre el deseo de un Dios ignoto ${ }^{16}$ que dicta su ley, sobre el modelo de un nous formal perfecto y superior, sobre la determinación de una naturaleza animada, propositiva o puramente racional parece mítico en este tiempo; como parece que se lo pareció a Epicuro, que ya denunció como tal, sin ir más lejos, el creer que "los cuerpos celestes, seres felices e inmortales (...) al mismo tiempo tienen deseos, ocupaciones y motivaciones contrarios a esa esencia" 17 .

La vieja filosofía epicúrea sigue inspirándonos, igual que inspiró buena parte del pensamiento moderno y contemporáneo.

Así, entendemos que el facto político, el constructo artificial que es lo político, es y debe ser el cociente del deseo de los cuerpos humanos que lo edifican, y que no asumir el alcance de tal cosa hace de la política su contrario: guerra ${ }^{18}$.

El cuerpo como domine. La política, pues, como ley del deseo ${ }^{19}$.

Si bien, de un deseo que no es deseo libérrimo.

La razón opera con y a partir del deseo, del placer, de lo que pide el cuerpo ${ }^{20}, \mathrm{y}$ en favor de éste.

"La carne concibe los límites del placer como ilimitados (...). Pero la mente que ha comprendido el razonamiento de la finalidad y límite de la carne (...) pone a nuestra disposición una vida perfecta" 21 .

No hablamos, pues, de una razón desnuda, estanca, pura al cabo, que opera sólo consigo misma, como cogitante fantasma agente, como si no perteneciera a un cuerpo paciente sin el que no existiría.

Así, nada tiene ese edificio movedizo de irracional: la razón es la que guía a los humanos por los abruptos y deslizantes senderos del placer, pues es el mejor método para señalarlos y jugar con ellos.

Despojar a la política de su fundamento trascendente o esencialista y traerla hasta el crudo y tocable placer acarreará consecuencias. Consecuencias que, según nos parece, siguen (y deben seguir) operando hoy.

\footnotetext{
En el sentido en que lo decimos: incluyendo alma, y razón con ella.

Y se dice en el sentido epistemológico estricto que el término designa.

Epicuro, Carta a Heródoto, en C. García Gual, op. cit., p. 113.

Seguimos en este punto el complejo dilema hobbesiano: política o guerra; y lo decimos en ese sentido. Obviamente los confines que definen guerra y política o paz y guerra no son tan claros en el campo real. Los manejamos así con propósito teórico y así hay que entenderlos. El mismo Hobbes advierte de la latencia perenne de la guerra en el estado político y resulta obvia también la presencia, más o menos asomada, de lo político en el estado natural.

19 El hoy muy mentado Thoreau, en el arranque de su Civil Disobedience, parece que tiene claro el asunto: "The government itself, which is only the mode which the people have chosen to execute their will...".

20 Digamos aquí, por precisión, con Epicuro, mejor, "la carne" (sarkos). La distinción entre soma y sarkos, cuerpo y carne es fundamental: el alma es cuerpo, pero no carne.

21 Epicuro, Máximas capitales, en C. García Gual, op. cit., p. 147.
} 


\section{La revolución epicúrea: contra la Academia y el Liceo}

En Galileo, de Liliana Cavani (1968), Paolo Sarpi le advierte a Giordano Bruno, pocos días antes de ser éste quemado: "El hombre ha sido creado para fines últimos". A lo cual el napolitano replica: “¿Usted ha encontrado en su anatomía músculos y huesos? ¿Dónde están los fines últimos?"22.

El diálogo hace síntesis bien elocuente del tono antiteleológico que en el XVII esgrimirán Hobbes y Spinoza, y que, regresando por Lucrecio, llega a Epicuro, que fundó la base.

Huye y evita ese error ante todo: no imagines que la clara luz de los ojos se creara para que nosotros ver pudiéramos, ni que para avanzar por el camino a grandes pasos la extremidad de las piernas y los muslos sobre los pies flexionen (...). Porque ciertamente nada ha nacido en nuestro cuerpo para que podamos usarlo; sino que aquello que ha nacido procrea su uso ${ }^{23}$.

La idea y la letra las retomará Spinoza en la Pars prima de su Ethica, documento perfecto del antiteleologismo antropomórfico que en el XVII reaviva el pensamiento epicúreo. Pocas décadas antes Hobbes había diseminado con su despiadada burla del aristotelismo y su crítica al platonismo ${ }^{24}$ ese materialismo inmanentista, mundanizante, que usa, como venimos viendo, la inspiración de las viejas ideas del de Samos.

Contra la ética de formas de pilar platónico afirmó durísimo Epicuro: "Escupo sobre lo bello moral y sobre los que vanamente lo admiran, cuando no produce ningún placer"25.

Por si no hubiera quedado claro, dice más: "Yo exhorto a placeres continuos y no a esas virtudes vanas y necias que comportan embrolladoras ilusiones de frutos futuros" $" 26$.

Ese pulso antiacadémico y antiescolástico que define bien el barroco gassendiano-hobbesiano-espinosiano se lanza al cuello, al tiempo, de los dos cuerpos doctrinales que dibujaban el mundo griego.

Se pensó, se escribió y se habló en el Jardín contra esa antropomorfización ${ }^{27}$ que le supone anhelo y agencia a la trascendencia superior. Nada hay más allá que determine aquí: ni dioses, ni formas, ni géneros generalísimos, ni naturaleza animada, orgánica, intencional.

Epicuro prezanja el asunto teológico y el teleológico de un trazo, con una idea tan clara y distinta como cortante: no tiene sentido que un ser superior y completo desee nada, intente nada, pues ocupaciones, preocupaciones, cóleras y agradecimientos no armonizan con la beatitud propia de un ser de beatitud perfecta unida a la inmorta-

\footnotetext{
Traducimos el diálogo original.

Lucrecio, De rerum natura, en C. García Gual, op. cit., pp. 118-119.

Lo cual no fue óbice para dejar escrito que Platón "was the best Philosopher of the Greeks". Cf. T. Hobbes, op. cit., pp. 521-522.

Epicuro, Fragmentos de Usener, en C. García Gual, op. cit., p. 164.

Ibidem.

Más de alma que de carne, en la idealización; de intención e inteligencia, los recursos desnudos de la acción y el deseo humanos.
} 
$\operatorname{lidad}^{28}$. Es insensato creer que los seres felices e inmortales (...) al mismo tiempo tienen deseos, ocupaciones y motivaciones contrarios a esa esencia ${ }^{29}$.

La naturaleza progresará de agente a inerte.

En un todo sin intención, sin agencia, sin fines fijos por prefijados ¿qué determina lo debido, que era lo querido por la Superagencia, digámoslo así?

En un mundo en que las cosas no suceden porque las quiere un $\operatorname{Dios}^{30}$, al hombre que desea le toca decidir, precisamente porque desea, razona y puede, porque desentraña y busca el placer, y desdeña el dolor: y en función de eso, pues no otra cosa hay más original ni más postrera en el desencadenamiento de la acción. Ni otro criterio para decidirla, para elegir la buena; para definir el bien, en fin, que habrá de componer sobre esa movediza y abigarrada base. La ética, gira con todo ello tanto como girará la física con la advención de Copérnico.

La idea de un humano preprogramado por su esencia, un nous, un cosmos o una voluntad superiores no cabe en esta concepción de lo existente: de un humano que para ser propiamente tal y no una entidad defectuosa haya de funcionar según esa programación pre-puesta, según un canon perfecto al que, de existir, no tiene acceso epistémico. Ni cabe, por supuesto, la misma idea aplicada a la naturaleza toda.

"No hay ninguna sociedad humana (natural), cada uno vela por sí mismo"31.

Ya el terreno concreto de los asuntos públicos una idea clásica se viene abajo y con ello, en buena parte, nace la política moderna tras acrobacia conceptual que faculta el a su vez clásico materialismo Epicúreo ${ }^{32}$ en el seiscentesco cerebro hobbesiano. El barrido de la noción aristotélica, expresivamente teleológica ${ }^{33}$, del hombre como zoon politikón, por parte de Hobbes, que más bien fija al humano como zoon polemikón ${ }^{34}$, acaba gestando una idea que describe perfectamente el giro hobbesiano en la metafísica moderna y, con ella, en la política: el hombre no es zoon politikón (por ventura de su esencia), pero le conviene serlo (por ventura de su anhelo). Y le conviene significa no otra cosa que que lo desea, que tal le place porque tal le faculta desear y seguir deseando: que, en fin, si opera según la línea recta de la recta razón (recta, que no desnuda), llegará a concluir necesariamente, tras deliberación que le liberará de otros deseos competidores y competitivos ${ }^{35}$, que las causas pasionales en que su fisiología se ve envuelta en vida, filtradas por esa operación calculante que distingue al humano y lo hace naturalmente y razonablemente libre, quieren la vida política ${ }^{36}$. En el terreno epicúreo el problema se

Epicuro, Carta a Heródoto, en C. García Gual, op. cit., p. 112.

Ibidem, p. 113.

30 O por ventura de un primer motor que fija todo lo que ha de pasar, o al albur de un canónico mundo perfecto trascendente, cuyos retazos imperfectos son nuestro mundo, que ha de tender, impotente, al modelo, o según cualquier variante teológicoteleológica por el estilo.

31 Epicuro, Fragmentos de Usener, en C. García Gual, op. cit., p. 211.

32 Clásico, si bien opuesto a los flujos dominantes.

33 Pues funde fin cosmológico con fin humano, por así decir: el hombre perfecto, el hombre acabado en el cosmos es un hombre cívico.

34 Permítasenos la libertad en la expresión, y entiéndase bien: animal potencialmente en guerra siempre; $y$ actualmente en guerra siempre, salvo que se artificie la política.

35 Lo decimos en el sentido hobbesiano que el inglés apunta en T. Hobbes, op. cit., p. 46: "The whole summe of Desires, Aversions, Hopes and Fears, continued till the thing be either done, or thought impossible, is that we call Deliberation".

36 Vida política que, para serlo, en el terreno hobbesiano implica acuerdo y paz, que es a lo que las pasiones básicas abocan: "The Passions that encline men to Peace, are Feare of Death; Desire of such things as are necessary to 
describirá en términos de placer y dolor, sobre un fondo similar y con un acabado en sintonía:

Respecto a todos aquellos animales que no pudieron concluir sobre el no hacerse ni sufrir daño mutuamente, pare ellos nada hay justo o injusto. Y de igual modo también respecto a todos aquellos pueblos que no pudieron o no quisieron concluir tales pactos sobre el no hacer ni sufrir daño ${ }^{37}$.

No es el hombre cívico, político por naturaleza; lo es por artificio y por placer: porque quiere, porque puede y porque sabe hacerlo, hacerse así.

"Quienes han tenido la capacidad de lograr la máxima seguridad en sus prójimos, consiguen vivir así en comunidad del modo más placentero, teniendo la más firme confianza, $\mathrm{y}$, aun logrando la más colmada familiaridad" ${ }^{\prime 38}$.

Fijar el placer, el querer como el cimiento de todo el edificio humano ${ }^{39}$ muda la cara y la entraña entera del pensamiento, de la ética y la política. Las consecuencias, en esos campos y en su sub-área jurídica, serán revolucionarias. El nuevo criterio maestro humaniza, fisiologiza el pensar y el hacer. Y tal no se le escapa a Epicuro, ni la enseñanza de Epicuro se le escapó a Hobbes. Si no hay mandato o modelo superior trascendente que ordene (sea en forma teleológica, teológica o canónica: fantasmagorías en este terreno materialista), y los humanos anhelan, buscan lo incompatible o incompartible, habrá indeseada guerra o deseado pacto. Por razones obvias, y hasta tautológicas, se querrá y se deberá querer lo querido: pacto y seguridad que franqueen vida y deseo, vida y placer.

"La justicia no era desde un comienzo algo por sí mismo, sino un cierto pacto sobre el no hacer ni sufrir daño surgido en las relaciones de unos y otros en lugares y ocasiones determinados" ${ }^{\prime 4}$. Un no sufrir daño que en la Máxima capital. 40, como veíamos, se enuncia como la máxima seguridad, la garantía del modo más placentero de vida que permite la comunidad que la salvaguarda.

La propia nota marginal de Hobbes que titula el párrafo que transcribimos anuncia la idea: The End of Common-wealth, particular Security.

The finall Cause, End, or Designe of men, (who naturally love Liberty, and Dominion over others,) in the introduction of that restraint upon themselves, (in which wee see them live in Common-wealths,) is the foresight of their own preservation, and of a more contented life thereby ${ }^{41}$.

Consecuentemente, esos pilares políticos se extenderán a la justicia: "Según la noción común el derecho es lo mismo para todos, es decir, lo que es provechoso al trato comunitario. Pero el particular de un país y de momentos concretos no por todos se acuerda que sea el mismo"42.

commodious living; and a Hope by their Industry to obtain them. And Reason suggesteth convenient Articles of Peace, upon which men may be drawn to agreement" (Ibidem, p. 98).

Epicuro, Máximas capitales, en C. García Gual, op. cit., p. 149.

Ibidem, p. 150.

Fijarlo, pues, en el cuerpo, en este nuevo cuerpo animado que pinta Epicuro.

Ibidem, p. 149.

T. Hobbes, op. cit., p. 85 .

Epicuro, Máximas capitales, en C. García Gual, op. cit., p. 149. 
No es nada la justicia antes de que los hombres acuerden crearla y someterse a ella: "Lo justo según la naturaleza es un acuerdo de lo conveniente para no hacerse daño unos a otros ni sufrirlo"43.

Y, de nuevo, Hobbes en la misma línea:

The notions of Right and Wrong, Justice and Injustice have there [en un estado prepolítico, antes del pacto que lo remede] no place. Where there is no common Power, there is no Law. (...) Justice, and Injustice are none of the Faculties neither of the Body, nor Mind. (...) They are Qualities, that relate to men in Society, not in Solitude ${ }^{44}$.

When a Covenant is made, then to break it is Unjust: And the definition of Iniustice, is no other than the not Performance of Covenant ${ }^{45}$.

La postura epicúrea, como luego la hobbesiana, aboca al humano a un mundo humano, quizás demasiado humano; a un mundo terroso, tal vez más árido de lo aceptable o lo soportable. ¿O lo aceptable es lo verdaderamente insoportable? ¿Consuela el engaño cuando hace aguas ${ }^{46}$ ?

La verdadera revolución epicúrea ${ }^{47}$, nos parece, es ese protohumanismo helenista que nos coloca, desamparados (pues la naturaleza y los dioses no tienden su mano y todo se juega aquí y por nosotros), en el centro de la decisión y la acción, y que fraguará propiamente en la modernidad con el influyente pensamiento (inmanentista, materialista) ético y político de Hobbes y Spinoza.

\section{Epicuro: anhelos y desventuras humanos, entre el placer y el dolor}

Al margen del quizás más conocido consejo de Epicuro, directo y literal en el testimonio laerciano (el sabio no hará política) ${ }^{48}$, su doctrina antropológica simplifica, complicándola hasta hoy, el eje sobre el que virarán las acciones humanas. Como resulta obvio, siendo la política el marco dentro del cual se ejecutan los actos, tal eje explicará (y trataremos de sostener que incluso justificará) por qué son esos actos y cómo dirigirlos. Y, lo que es más, cómo dirigirlos correctamente: así en el sentido

\footnotetext{
Ibidem.

44 T. Hobbes, op. cit., p. 98.

45 T. Hobbes, op. cit., p. 110.

46 Contra las vanas opiniones, la filosofía vana, contra supersticiones, supercherías y mitos escribieron Epicuro y Hobbes: "No tiene ya nuestra vida necesidad de irracionalidad y de vana opinión." (Epicuro, Carta a Pítocles, en C. García Gual, op. cit., p. 135). "Lastly, the Metaphysiques, Ethiques, and Politiques of Aristotle, the frivolous Distinctions, barbarous Terms, and obscure Language of the Schoolmen, taught in the Universities, (which have been all erected and regulated by the Popes Authority,) serve them to keep these Errors from being detected, and to make men mistake the Ignis fatuus of Vain Philosophy" (T. Hobbes, op. cit., pp. 540541.) Léanse, como especialmente ilustrativos, los párrafos inmediatamente anteriores. El propio título del capítulo, el XLVI, el penúltimo del Leviathan, es autoelocuente: "Of Darknesse from Vain Philosophy, and Fabulous Traditions".

47 Probablemente aún hoy inconclusa, pues pudiera leerse la historia como una desmitificación progresiva, a todas luces no completada.

48 Y huirá del gobierno ciudadano como daño y perturbación de la felicidad. (Epicuro, Fragmentos de Usener, en C. García Gual, op. cit., p. 68.)
} 
físico (natural) como en el moral, en una limpia delimitación del bien y el mal, de lo bueno y lo malo, en consonancia con dos sensaciones bien conocidas en y por el animal humano. El placer, el dolor.

"Todo bien y mal reside en la sensación"49. Sensación que, según su cualidad, determinará lo bueno y lo malo: "Todo placer (...) es un bien; (...) también cualquier dolor es un mal" 50 .

Hobbes recoge la idea y la recompone a su modo; más claramente, si cabe.

"Morall Philosophy is nothing else but the Science of what is Good, and Evill, in the conversation, and Society of man-kind. Good, and Evill, are names that signifie our Appetites, and Aversions" 51 .

Pero tan limpia y clara fijación acaba dando en complejísimo criterio, tanto si se la entiende bien como si se la entiende mal.

Perdernos, como se ha hecho desde que Epicuro pensó y enseñó, en malentender y ridiculizar la doctrina epicúrea no nos lleva a nada más que a perder el valor clarividente de ese revolucionario pensamiento helenístico que batió la modernidad y nos llega hasta hoy con toda su fuerza. El bien, el mal, lo bueno, lo malo no dependen de incógnitas pre-configuraciones normativas del universo y del humano (que destilará su virtud innata), sino del deseo y la aversión, del placer y el dolor, de buscar lo que place y evitar lo que duele, y de toda la complejidad que tal supone ${ }^{52}$.

La caricaturización del epicureísmo, que a menudo parte de una interpretación descuidada por gran parte de la tradición que lo hace maldito y lo prohíbe, parece temer la yema revolucionaria que sí tiene, ciertamente, como hemos ido viendo.

Mucho más se usó ayer para atacar, pero aún hoy se usa epicúreo como sinónimo de libertino, no en el sentido del libertinage érudit ${ }^{53}$, sino en el más gráfico del libertino popular por excelencia, el veneciano Casanova.

Entre otras razones que se adivinan, detrás de la confusión vemos también la habitual disfunción filológica con que suele arrancar buena parte de las disputas filosóficas. No nos entretendremos más de lo necesario en la cuestión, pero sí apuntaremos lo que nos parece básico. Cuando se habla de placer, hoy y ayer (y, por lo visto, anteayer, pues ya en la Grecia helenística Epicuro pasó por depravado $)^{54}$, por ventura de razones que se nos escapan y que darían para un bella disquisición sobre la condición humana, parece entenderse sin más lo que podríamos llamar genéricamente placer carnal, y así se ha tomado tantas veces la máxima epicúrea de que el placer es criterio maestro de acción, con el consiguiente escándalo que generará detracción a lo largo de la historia y hasta nuestros días. Poco nos quedó del maestro de Samos,

\footnotetext{
Epicuro, Carta a Meneceo, en C. García Gual, op. cit., p. 141.

Ibidem, p. 143.

T. Hobbes, op. cit., p. 122.

52 Sin duda, el par desire-aversion sobre el que Hobbes edifica todo el edificio de creación antropológica, es equiparable en muchos aspectos relevantes (si no equivalente, si no idéntico) al par epicúreo placer-dolor.

53 Como era de sospechar, por supuesto, Hobbes igualmente fue acusado de inmoral libertino; y además tuvo relación con el libertinage érudit de su tiempo, incluso fue exaltado por los libertinos, junto con Gassendi. Cf. el excelente trabajo al respecto de Malcolm "Hobbes and the European Republic of Letters", en Malcolm 2002, especialmente, pp. 502-504

$54 \quad$ El ambiente histórico lo pinta bien el pasaje de Lactancio en sus Institutiones divinae (bk. III, ch. 17) citado por Wilson (2008) en traducción de McDonald: "In The Wrath of God, his jeremiad against Epicurean morals, the complement to his creationist tract, The Workmanship of God, he referred to «vicious and nefarious men, who pollute all things with lusts, plague others with killings, defraud them, steal and perjure; they spare neither their relatives nor their parents, and they ignore laws and even God himself »".
} 
pero ninguna letra que sostenga ese modo de leer su pensamiento. Ni letra ni espíritu. Antes bien, la moderación es capital ${ }^{55}$. En el término placer y sus denotaciones, pues, se juega el asunto.

Si nos atenemos al testimonio estrictamente textual, resultan difíciles de entender los malentendidos acerca del concreto asunto del placer en la teoría epicúrea. Y sólo pueden atribuirse a disputas ideológicas que trascienden ese concreto punto. Y ahí sí estaría justificada la oposición que quiera hacerse, si se temen las consecuencias de una idea que revoluciona la tradición, como hemos ya apuntado. Sin embargo, en lo que al singular y preciso elemento "placer" concierne, elemento seminal que traerá consigo lo demás, sí cabe aclarar lo que, por otro lado, parece transparente en los textos del maestro del Jardín. La limpia distinción entre placer catastemático y placer cinético, entre placer estable y placer fugaz, en cierto modo equiparables al placer del espíritu y al de la carne ${ }^{56}$, da ya la clave. Y debe entenderse que unos y otros son placeres, y como tales, perseguibles. No obstante, se preferirá el catastemático por una razón sencillísima, que se adivina: proporciona, cuantitativa y cualitativamente, más placer; $\mathrm{y}$, en el anverso, ahuyenta el dolor.

Epicuro, no obstante, la parquedad de lo que nos ha llegado, lo dice claro: Son mayores los placeres del alma ${ }^{57}$, los placeres sostenidos, catastemáticos (la hedoné katastematiké). Por una razón fundamental: "Donde haya placer, por el tiempo que dure, no hay dolor"s8.

Así, queda el placer no como attimo di solletico generale $e^{59}$ : sino en tanto bienestar sostenido (placer catastemático), que pasa a ser la eudaimonía epicúrea, por encima de una completud aristotélica que, en consecuencia, con esa doctrina, sólo se da al final de la vida. Si bien es cierto que la bios theoretikos de Aristóteles puede sonar como goce perenne, en ese ámbito es canon de vida feliz y perfecta, pero en el sentido propio de completa, de potencia realizada, de alcance y conquista de aquello para lo que se está hecho, y es perseguible como tal, no por el placer inmediato que proporciona. La distinción es radical, como lo son sus consecuencias.

Por todo ello, la valiosa discusión filológica sobre los problemas del uso del vocablo griego original, hedoné, nos interesa ahora sólo en la medida en que ilumina lo anterior. Sea como fuere, el placer, algo que depende de la sensibilidad del animal humano, tan particularmente dotado para manejarlo, es el criterio; y la razón, esa particularísima capacidad, el mejor recurso para la administración de los distintos tipos de hedoné: cinética, catastemática, de la carne, del espíritu.

Tal fundamento ético, claro, incidirá en la política directamente: el placer (la hedoné general) es "bueno" per se, perseguible y fin verdadero, independientemente de cualquier otra circunstancia que no tenga que ver con él; $y$, en consecuencia, criterio último y único de bondad y de acción, de deber. El pasaje de la Carta a Meneceo, ya visto, es transparente:

55 Y lo será, como no puede sino esperarse, por razones de placer, pues otras no hay: el hartazgo, las consecuencias en modo de dolor que el placer pudiera portar.

56 Todos ellos dentro del campo semántico de la hedoné griega. Al respecto de la cuestión filológica y conceptual, iluminador García Gual en Epicuro, op. cit., pp. 154, 155, 162-170.

57 Cf. Diógenes Laercio, Vidas y opiniones de los filósofos ilustres (traducción, introducción y notas de Carlos García Gual), Madrid, Alianza, 2007, p. 565.

58 Epicuro, Máximas capitales, en C. García Gual, Epicuro, op. cit., p. 145.

59 Que también, en la medida en que no traiga dolor y contribuya a extenderlo. Permítasenos la enunciación italiana, tan precisamente sonora y expresiva. 
El placer es principio y fin del vivir feliz. Pues lo hemos reconocido como bien primero y connatural y de él tomamos el punto de partida en cualquier elección y rechazo y con él concluimos al juzgar todo bien con la sensación como norma y criterio. (...) Todo placer (...) es un bien ${ }^{60}$.

Con eso habremos de vérnoslas en el campo de la ética y de la política, como en todos los demás.

\section{Placer y política}

Es precisamente el placer y el dolor lo que delata la condición humana. Placer que es deseo, y deseo que en su envés negativo incluye aversión, dolor, lo que mueve al hombre en este translúcido mundo de materia y movimiento. Placer que acoge ese placer más alto porque es placer igual. Placer que trasciende, pues, lo meramente carnal, y que a la vez lo incluye. Deseo que opera con el cálculo racional para gestionarse en función, precisa y circularmente, del deseo. Y (y aquí queríamos llegar ahora), sobre esa base, se edificará todo lo que el humano haga: así, la política, hija del deseo, del placer, será y deberá ser producto de lo que el cuerpo, un cuerpo no sólo carnal, deseará. $\mathrm{O}$ determinará, si se quiere, en precisión, si bien entendida, más apropiada.

Por decirlo en términos habituales: no destacamos que el deseo determine el ser político, pues tal cosa pudiera aceptarla bien que mal cualquier línea de pensamiento, sino que más allá, de la mano de Epicuro y Hobbes, y ajustando ese pensamiento, tratamos de sugerir que el deseo, el placer, el querer, el anhelar, puestos en juego y tamizados y guiados por la razón, fundan y determinan el deber ser político. El querer, el placer, obvio es, de los cuerpos que lo crean y lo deciden: pues el deber ser, la ética, la política son invento de humanos bien corpóreos, que juzgan como lo bueno una concreta concatenación causal cuyo efecto es el deseado por ellos. Y en el marco, claro está, de lo posible, definido por las condiciones materiales (causales), tanto de los actores-autores como del escenario en que se juega ${ }^{61}$.

En definitiva, y, además, tal como la entendemos y por las razones expuestas, la postura epicúrea no es normativa en sus fundamentos: es estrictamente descriptiva. Al menos en su base. Y la distinción, en este caso, como en el de otros malditos (Maquiavelo, Hobbes) es capital. Así, entre otras cosas, no cabe atacar a Epicuro como vicioso o depravado, sino, como mucho, en el peor de los casos, de imprecisión gnoseológica, por así decir. El humano, por función de las leyes de la physis que nos es dado cotejar, fisiológicamente, físicamente, realmente, funciona así; la naturaleza procede así: el humano tiende a lo que le da placer y huye de lo que le da dolor; y nada hay más allá ni más aquí de eso $^{62}$. Es cierto que, por estar el placer, el

\footnotetext{
Epicuro, Carta a Meneceo, en C. García Gual, op. cit., p. 143.

La naturaleza toda, el mundo todo, con sus leyes, que no manan de arbitrio transhumano alguno.

Recordemos el pasaje de la Carta a Meneceo. 129: “[el placer] es el bien primero y connatural”. Rico, el comentario de P. Oyarzún: "El vocablo syngenikón alude al hecho de que la búsqueda del placer está inscrita en el viviente desde el instante de su nacimiento y vale para él, en esa medida, como el fundamento de toda preferencia y de toda aversión, y pone, en el hombre, las bases para el discernimiento de lo bueno" ("Epicuro: Carta
} 
querer en el eje de toda su doctrina, el hiato entre ambas instancias (la descriptiva y la normativa) se enlaza de manera que toca la misma matriz de lo humano y se funde en un modo espectacular cuya potencia aprovechará Hobbes siglos más tarde para justificar el artificio de la política: la fijación de la preservation como tendencia natural, que por ventura de la fisiología humana será necesariamente deseo primero $^{63}$ que faculta la continuidad del anhelar. Tal factor prístino desencadena la fusión: se debe buscar la política porque necesariamente se quiere sobrevivir, y la política será la vía de la paz, el artificio humano más valioso, pues ha de funcionar como sortilegio contra la selva que resulta la circunstancia humana sin ella: sin la política, y sin la paz. O, dicho de otro modo: la norma dicta erigir el constructo político, buscar la paz porque el humano está hecho de tal modo que su condición, su ser es querer y querer eso que le permite querer y querer. Un constructo político que para serlo será confluencia del deseo de todos los que lo construyan: los humanos que, en ese acto deseado, devendrán ciudadanos, la más alta virguería de la capacidad poiética del animal erecto. Así, la política entendida como institución convenida por todos y cada uno, a un tiempo se autoexplica y se autojustifica, casi en la misma instancia: ha de hacerse porque las leyes que rigen el hacer y el desear del animal que la desea ${ }^{64}$ operan necesariamente de ese modo, abocándolo a desear hacerla. Nada hay más allá del anhelo humano ${ }^{65}$, que sepamos, capaz de determinar el deber ser, y ahora quizás trascendemos la doctrina hobbesiana: hágase pues lo que se quiera, lo que pida el cuerpo. Eso se debe, si se quiere; y, pues se quiere, se debe. El pacto, en consonancia y como veremos, será el elemento que gestione el haz de deseos diferentes y haga del ser el deber ser en el terreno político: contiene y manifiesta el querer común y el compromiso común a un tiempo, y con ello obliga. El factor y la instancia desiderativa en la raíz del deber, pues así en la raíz de la acción, funden la norma que rige con el contenido efectivo del querer. Otra cosa, mucho más compleja que la simpleza de la enunciación, será calcular ese contenido y las vías que a él lleven, por las que, si se acierta en la captura de la concatenación causal, habrá necesariamente que transitar en pos del escurridizo objeto de deseo, tanto más escurridizo cuanto mutante.

Y será, por tanto, también factor clave el mudamiento del deseo, que evidentemente lo es del objeto del deseo y no del deseo en sí, pues éste es, si cabe y como cimiento primero, inmutable en tanto incesante, en cuanto siempre operando igual: deseando ${ }^{66}$. Así, esa veleidosidad, siquiera sea por razón de hartazgo, de la saciedad que el deseo igual da, al revés que la fijeza de una norma moral, tan fija en la virtud clásica como en la razón kantiana, determinará la concomitante mudanza del constructo político, que en su condición de voluntario y factible (en su versión mecanicista moderna), querrá erigir su producto flexible y capaz de cambio. Así, la política efectual: si se quiere eficaz y longeva, sus instituciones habrán de prever el factor y

a Meneceo" (Introducción, traducción y notas), en Onomázein 4, 1999, pp. 403-425, aquí. p. 417).

63 Si bien nos parece precisamente ese objeto concreto del desear uno de los puntos más controvertidos del pensamiento hobbesiano. Nos interesa más bien la idea de localizar la base del bien en el desear, el gozar en su pura verbalidad, en su versión formal sin contenidos, idea bien ubicua en la obra de ambos.

64 Las laws of nature hobbesianas, teoremas, tal como las describe en los capítulos XIV y XV del Leviathan.

65 Racional y falible.

${ }_{66}$ Hobbes nos enuncia la idea con un fraseo bello en uno de los pasajes fundamentales del Leviathan: "a perpetuall and restlesse desire of Power after power, that ceaseth onely in Death" (T. Hobbes, op. cit., p. 75.). Poder para conseguir lo deseado, claro está 
facilitar su despliegue de la manera más eficaz posible.

La línea de pensamiento que manejamos ahí nos lleva; el mismo Epicuro no puede escaparse a esa consecuencia necesaria de su materialismo hedonista:

Cuando, sin aparecer variaciones en las circunstancias, resulta manifiesto que las cosas sancionadas como justas por las leyes no se adecuan ya en los hechos mismos a nuestra prenoción de lo justo, ésas lo acentúan. Cuando, al variar las circunstancias, ya no son convenientes las mismas cosas sancionadas como justas, se ve que eran justas entonces, cuando resultaban convenientes al trato comunitario de los conciudadanos, y luego ya no eran justas, cuando dejaron de ser convenientes ${ }^{67}$.

$\mathrm{Ni}$, consecuentemente, Hobbes:

And because the constitution of a mans Body, is in continuall mutation; it is impossible that all the same things should alwayes cause in him the same Appetites, and Aversions: much lesse can all men consent, in the Desire of almost any one and the same Object. But whatsoever is the object of any mans Appetite or Desire; that is it, which he for his part calleth Good: And the object of his Hate, and Aversion, Evill ${ }^{68}$.

Dicho esto, resta apuntalar lo que se escapa. Pudiera quedar la sensación de que se está proponiendo una política loca, no ya flexible sino tan fugaz que aparece imposible de fraguarse en la escena extradramática. Lo que cambia es el objeto de deseo, no la propia posibilidad de desear, de obtener placer, que es, precisamente, el elemento que ase de nuevo al mundo esa levedad de lo mundano ${ }^{69} ; \mathrm{y}$ de nuevo en Hobbes, de bruces: el deseo básico es la supervivencia, y la posibilita la paz, deseo primario y ley de naturaleza primera ${ }^{70}$. Pues la paz enmarca la vida y una vida que permite el flujo inmarcesible de deseo en que consiste ésta. Algunos de sus subcontenidos-subobjetos, carnales y espirituales ${ }^{71}$, todos deseo, todos placer, los enumera Hobbes directamente:

"Desire of Ease, and sensuall Delight, (...) Desire of Knowledge, and Arts of Peace, (...) desire of leasure; and consequently protection from some other Power than their own"72.

En consecuencia, la política, deseada, programada y erigida sobre el covenant de todos no podrá ignorar el factor mutante: de hacerlo, se desvanecerá antes que las demás ingrávidas construcciones humanas que sí conocen las leyes del artificio y las convienen; y que caerán, como todo lo de este mundo, el único, pero ya usadas y gozadas.

Dos consecuencias inmediatas y capitales nos quedan, pues, de lo dicho respecto al placer como fundamento de lo político:

\footnotetext{
Epicuro, Máximas capitales, en C. García Gual, op. cit., p. 150.

T. Hobbes, op. cit., pp. 40-41.

Que lo sea no lo hace despreciable o apreciable: simplemente tal es; y basta.

Cf., por ejemplo, el capítulo XIV del Leviathan.

Válganos el hiato en lo que es más bien diptongo.

Ibidem, p. 76. El hombre desea, y desea paz y seguridad porque necesita paz y seguridad para colmar el deseo, para colmar el placer. Con ese objeto artificia la política, tan sencillo, tan complejo.
} 
El contenido material del placer, que es el criterio maestro, no está fisiológicamente fijado en la especie ${ }^{73}$, sino que depende de cada paciente. Así, en la base, la diversidad, la heterogeneidad ética: cada cual considera qué es placer, qué dolor, hasta el punto, como tratábamos de sugerir, de que la misma causa lo es de placer y de dolor, y no sólo cuando se da en diversos individuos, sino incluso en el mismo, en espacios de tiempo distintos. Tal cosa tendrá como consecuencia, no sabemos si trágica o afortunada, que la bondad de la acción dependa del sentir de cada cual.

Por tanto, si el bien, el deber dependen de tan escurridizo elemento, sólo caben la lucha exclusiva o el pacto inclusivo: por el placer. Lo primero será la selva; lo segundo, la política.

\section{Pacto y placer}

En una antropología como la epicúrea en que los humanos son iguales en tanto buscadores de placer, parece la mejor la opción pacífica. Y ésta necesitará, pues, del convenio, que supone la condición del beneficio mutuo, del placer mutuo, del deseo mutuo. La pérdida, cierta restricción del goce individual: pérdida nimia si se evalúa cuánto se obtiene en el acuerdo ${ }^{74}$.

En un universo que enmarca un universo humano como el que pergeña la tradición materialista epicúreo-hobbesiana sólo el convenir o su ausencia definen la opción guerra o paz, ciudad o selva. La imposición forzosa de una facción cabe (aunque la revolución siempre es posible, y siempre latente): pero no es política, es guerra. La política viene definida por el deseo, y por el deseo de hacerla para ganar lo deseado. Por parte de todos: en esa edificación, ciudadanos. En un estado pre-político, de naturaleza, en la terminología hobbesiana, el placer, el deseo están sin institucionalizar, y su uso ad libitum, más que justificado, queda explicado por los procesos mecánicos, en este caso fisiológicos ${ }^{75}$. Si bien es cierto que, en un entorno mecánico y libidinoso como el que nos ocupa, la explicación justifica, por ventura de una circularidad moral que empieza y acaba en el humano (elemento deseante en este mundo, inmanente y de orden mecánico), la guerra ubicua... ¡Salvo!... que se convenga, pues ése es el elemento clave que pasa a determinar el deseo nuevo, que será deseo limitado por lo que se pacte entre todos los anhelantes. Nos vale aquí también la ya traída Máxima Capital 31, en la que Epicuro sostiene que lo justo depende de un acuerdo de lo conveniente para no hacerse daño unos a otros ni sufrirlo. El contenido de la convención, así, sí define lo bueno y lo justo ${ }^{76}$ y doma la libido loca de la selva.

3 Queda aparte, claro está, el primario: la vida que faculta seguir obteniendo placer.

74 La idea la enuncia con sencillez clarividente D. Gauthier: "Contractarian morality-the morality of mutal advantage-is a minimal constraint on the pursuit of one's interest" (Moral dealing: contract, ethics, and reason, Ithaca; London, Cornell University Press, 1990, p. 5).

75 Pues no hay fines naturales a los que tienda el hombre para completarse, ni mandatos divinos que puedan conocerse: no hay cánones, en fin, de lo bueno y lo justo antes del acuerdo entre cuerpos humanos, como hemos venido viendo.

76 La idea está en Hobbes, enunciada en términos del XVII: "For in the condition of men that have no other Law but their own Appetites, there can be no generall Rule of Good, and Evill Actions. But in a Common-wealth this measure is false: Not the Appetite of Private men, but the Law, which is the Will and Appetite of the State is the measure" (T. Hobbes, op. cit., p. 531). 
En definitiva, si no se conviene ${ }^{77}$, no hay política, no hay civilización. Hay un convivir que no es tal porque no es propiamente vivir con, sino vivir contra: no política, pues. Y para ese viaje no hacen falta alforjas ningunas. Si no se pacta en función de lo que nos pide el cuerpo, contraviviremos cual lo hacen hienas, leones, gacelas y monos, animales como nosotros. Pero incapaces de erigir un parlamento. Es la potente razón humana lo que nos distingue de las hienas o los macacos, es el lenguaje que inventa lo nuevo, es la destreza de hacer lo casi inverosímil, pero sobre todo es la capacidad para instituir lo político: un ámbito complejísimo de convergencia de todos los cuerpos humanos que piden lo que diverge. En sabanas minadas, en mundos de acecho y traición, de lucha embarrada, de colmillos y filo de cuernos, de bofetada y fuego el placer del individuo vale tanto como el de una gacela perseguida por un guepardo. O tanto como el del felino que no puede alcanzarla y morirá de hambre. Parece obvio que el interés de todos y cada uno está de tal modo ligado que es difícil crear compartimentos estancos. O quizás no resulta tan obvio y ahí la clave. Pero dado lo apuntado, nos parece necia ceguera la que se ilusiona con la ebriedad del poder impuesto que perpetua la amenaza... hasta que cae, pues poco placer franquea. Todo en el ámbito de los asuntos humanos se fragua en el martillearse deseos y poderes. Y tendremos, según se forje la cosa, paz o guerra, civilización o selva: política o barbarie.

Fuerza y razón han de componer, sobre la base del anhelo, el marco del co-vivir, si es que se quiere, sobre la base del pacto; $y$, si se desea guerra, pues guerra habrá y nada habrá que convenir.

La erección de lo común, de lo público como institución soberana más poderosa que cualquier imposición privada, en forma de Estado, es el invento moderno que formatea la idea del contrato como matriz política. Y la matriz de esa noción clave para la política aún hoy, a su vez, nos vuelve hacia Epicuro, de nuevo a lo asentado en una sentencia ya leída, la Máxima Capital, 31: lo justo según la naturaleza es un acuerdo de lo conveniente para no hacerse daño unos a otros ni sufrirlo ${ }^{78}$.Y veíamos también cómo, más radicalmente, en la Máxima Capital 33, afirmaba que no existe la justicia antes de que se diera un cierto pacto sobre el no hacer ni sufrir daño surgido en las relaciones de unos y otros en lugares y ocasiones determinados.

Si bien la solución no disuelve. Es sólo el arranque, pues el problema brota directamente: ¿cómo acordar lo en principio incompatible, los deseos de cuerpos distintos que quieren distintos y opuestos placeres y desdeñan dolores distintos? Recomendable parece establecer un criterio base. Y la simple agudeza de Epicuro, de nuevo lo ofrece. Como anticipamos en las Máximas Capitales 36 y 38, la justicia se subordinará al trato comunitario, que será su fundamento:

De las leyes establecidas tan solo la que se confirma como conveniente para los usos del trato comunitario posee el carácter de lo justo, tanto si resulta ser la misma para todos como si no. Si se establece una ley, pero no funciona según lo provechoso al trato comunitario, ésta no posee ya la naturaleza de lo justo. Y si lo conveniente según el derecho cambia, pero durante algún tiempo está acorde

Y, de nuevo: los convinientes son todos y cada uno de los ciudadanos, pues que son los deseantes, quienes buscan el placer.

$78 \mathrm{Y}$ atendemos a los mismos orígenes de la tradición contractualista, sobre la que se basa el Estado moderno y el contemporáneo con él. Sólo antes los sofistas apuntaron trazas. 
con nuestra prenoción de lo justo, no por ese cambio es durante ese mismo tiempo menos justo para quienes no se confunden a sí mismos con palabras vanas, sino que atienden sencillamente a los hechos reales ${ }^{79}$.

¿Por qué fijar el criterio del trato común como el capital de la política? Tan sencillo como delicado: porque dado el panorama que nos es dado conocer, y en uso de la razón, parece que resulta la mejor estrategia. La más placentera. Por decirlo en términos descriptivo-normativos: en un marco en que distintos cuerpos viven juntos y desean y piensan (cuerpos de animales que son iguales en su capacidad para matarse ${ }^{80}$ ), éstos, en acción de su pasión, e intacta y diestra su facultad de razonar, desearán y deberán desear una paz sostenida y sostenible que les permita seguir viviendo juntos, gozando y deseando juntos lo que tengan a bien todos y cada uno, sólo limitados por las condiciones físico-fisiológicas del mundo y de ellos mismos, que incluyen, claro, la acción y el deseo propios y ajenos. A eso lleva su fisiología (capacitada para razonar y juzgar) ${ }^{81}$; el pacto, la herramienta maestra. Cuanto mejor se enmarquen los deseos comunes, la conveniencia mutua (la ophéleia epicúrea ${ }^{82}$, mejor irá el asunto. Ésa es, con matices aquí o allá, la conclusión hobbesiana que desarrolla y moderniza el antecedente epicúreo. Así las cosas, y tal es la idea que ordena la obra hobbesiana, según la leemos, los humanos artificiarán ese poder común acordado por todos que es el Estado, para sintonizar, con las disonancias propias del asunto, el concierto de placeres y dolores, de deseos y aversiones singulares que es la vida entre ellos.

Si el objetivo ha de ser la convivencia se hace necesario fijar métodos, caminos, medios para tal fin. Y ahí entra en juego otro recurso clave de técnica política: la ley, la justicia, que es espejo de valores comunes. Y es clave porque lo que hace a los humanos pertenecer a una comunidad política es su condición de ciudadanos: y ésta no viene definida por compartir territorio, lengua o raza, sino por participar de un sistema legal que los iguala, identifica en tanto tales. Esto es, por la atención de todos a unas mismas normas que sancionan y ejecutan los aparatos por ellos inventados y creados para ello. Ésa es la ciudadanía, eso es la comunidad política.

Ahora, todo lo que hemos venido apuntando más arriba al respecto de la concepción epicúrea de la justicia se ve con más luz y enfatiza el valor del trato comunitario como matriz legal, que es adonde pretendíamos llegar.

La búsqueda de placer gestará el destino del cuerpo de cada cual... y, de todos, en la dimensión política de la idea que pretendemos describir. En nuestras manos queda defendernos de la desolación, abiertamente, sin fantasmas.

\footnotetext{
Epicuro, Máximas capitales, en C. García Gual, op. cit., pp. 149, 150.

"The weakest has strength enough to kill the strongest" (T. Hobbes, op. cit., p. 94).

Volvamos a la Carta a Meneceo: "[Al placer] lo hemos reconocido como bien primero y connatural y de él tomamos el punto de partida en cualquier elección y rechazo y con él concluimos al juzgar todo bien con la sensación como norma y criterio" (Epicuro, Carta a Meneceo, en C. García Gual, op. cit., p. 143). Idea similar, también se la leemos a Hobbes: "Each individual is prompted by a particular natural necessity, no less than when a stone falls downwards, to act in pursuit of that which seems to him good [appetitionem sibi bonum], and to flee from what seems bad [fugam sibi malum]" (T. Hobbes, De cive: The English Version [J. H. Warrender, ed.], Clarendon Edition of the Works of Thomas Hobbes, 3. Oxford, Clarendon Press, 1983, p. 94).

82 Y la seguridad (aspháleia), la salvaguarda frente al lobo, téngase siempre en cuenta cuando de deseo y placer se habla: es elemento fundamental.
} 


\section{Remate}

El legado de Epicuro, pues, nos sigue siendo útil hoy porque la radicalidad cierta de su pensamiento remite todo lo que nos sucede al cuerpo: ese cuerpo que goza y sufre y que, en tanto tal, sigue siendo el mismo que fue en el siglo IV a.C. Y con él la política, hija, artificio deseado de ese cuerpo que no es sólo sensación que un alma ajena deplora, desprecia: muy al revés, esa alma es ese cuerpo. Siquiera parte de él: es él, intrincada en él está porque ella misma es cuerpo y porque sin él ${ }^{83}$ no es. Y su dolor y su placer se hacen razonables en ese mejunje erótico, odiante, trágico y, claro, cómico que es el cuerpo que desea y desdeña y decide, sin nada anterior ni domine dominante en el más allá, sólo condicionado por las propias leyes de su fisiología inserta en la mecánica physis. Obviamente, el filtro que el sistema nervioso centra ${ }^{84}$ hace de todo ese mundo (que es uno solo en el sentido relevante que la tradición materialista apunta), con su abrumadora complejidad ${ }^{85}$, contribuye a diseñar el panorama que cuerpo humano y humana política ${ }^{86}$ nos legan: la simplicidad de su fundamento (ese deseo de cada cuerpo, libre y cautivo a un tiempo, que determina en última instancia toda creación humana y, desde luego, quizás la más grandiosa, la política), acaba dando en la más complicada de las artes por virtud de, precisamente, la exuberancia de ese delicadísimo filtro que define el contenido material, concreto de los anhelos que habrán de convenirse para que la política sea política y no selva.

Nos parece que sigue sonando valiosa, incluso hoy, la propuesta epicúrea, radicalmente protoinmanentista en un ambiente de trascendencias y perfecciones diversas, tan brillantes como incógnitas, tan poéticas como intangibles: traerse a este mundo imperfecto, adusto a menudo y grato a veces, la eudaimonía posible; traer al cuerpo y desde el cuerpo a la vida humana toda y con ella, claro, a la política, a las tácticas de convivencia de sus poseedores, los humanos. Porque en esos recipientes semovientes y decidientes se juega la felicidad conocida. Más allá nada hay ni nada nos manda, que sepamos. Y, si lo hubiera, no estaremos vivos para vivirlo.

Es claro en Epicuro que no sólo la política debe supeditarse al cuerpo, por ventura del placer que pueda ésta regalarle ${ }^{87}$ : el propio saber, la propia ciencia ${ }^{88}$, la propia filosofía, sólo tienen sentido según ese claro y resbaladizo criterio. Como la amistad. "La amistad no puede separarse del placer y por ese motivo ha de ser cultivada, porque sin ella no puede vivirse en seguridad y sin miedo" 89 . Como todo. Y con ello, una vez más, una habitual circularidad de las fatigas filosóficas resulta elocuente. Diríase que el gran telos vital aristotélico, el bios theoretikós, que nada tendría de summum bonum ${ }^{90}$ desde una perspectiva epicúrea estricta, bien podría

\footnotetext{
Que es también carne, sarkos.

Por nominar a la psyché epicúrea con terminología contemporánea.

Capacidad razonante en él, y exquisitamente sentiente.

Cuerpo igualmente, como lo establece Hobbes ya en el arranque de su Leviathan, en fecundísima y más que explícita metáfora que ha hecho historia y que nos vuelve a remitir directamente al tema que aquí tratamos.

Placer que en su forma básica (la idea es clave y tiene la resonancia política directa), es seguridad (como en Hobbes), seguridad ante el dolor, ausencia de dolor.

88 "No hay que creer que haya otro objetivo final en el conocimiento de los fenómenos celestes (...) sino la serenidad del ánimo" (Epicuro, Carta a Pítocles, en C. García Gual, op. cit., p. 134).

89 Epicuro, Fragmentos de Usener, en C. García Gual, op. cit., p. 218.

90 O por decir mejor, en este contexto, de proton agathón.
} 
serlo en virtud de una circunstancia: que el cuerpo ejecutor de la contemplación experimentara con ella el más alto y sostenido de los placeres ${ }^{91}$. Según esta idea, $\mathrm{y}$ yéndonos más allá de lo que la doctrina de Epicuro escribe, el criterio maestro de la eudaimonía, su secreto, trascendería la precisa materialidad (concreción) aristotélica $^{92}$ para hacerse formal ${ }^{93}$. Da felicidad lo que da placer, y placer da lo que el cuerpo siente como tal. Esa formalidad parece remitirnos al carácter de individual de los criterios últimos. Y la falta de interés de Epicuro por adoctrinar políticamente parece coherente con ello; menos, quizás, el desinterés por lo político, siquiera sea por el alcance de los modos de organización común en el placer privado, digámoslo así, en lo que afecta sobre lo que el cuerpo pida. Las consecuencias de ese giro individual, además, son claras.

La política como marco y producto del deseo, del placer no podrá, así, definirse ni programarse en términos fijos, ni racionalmente autosuficientes, ni siquiera doctrinarios, pues los humanos, en bloque no tienden a un fin material, idéntico ${ }^{94}$ : dependerá de unas intersecciones posibles en ese modo formal que definan los anhelos fisiológicos (incluyamos, en esa versión íntegra de lo corporal, alma y nous) que, además, son cambiantes. Volvemos, claro, al covenant, a la imperfección de la política, a su delicadeza y a su carácter de decepcionante y útil.

Así, recogiendo lo dicho, el criterio maestro para definir y decidir las normas políticas concretas, que no podrá ser sino formal, no responderá a lo que una razón desnuda dicte, o a lo que una supuesta condición de hermandad entre los humanos determine, o a lo que una naturaleza teleológica fije, ni siquiera a un devenir histórico, ya material, ya espiritual, que necesariamente marque lo que de los humanos haya de ser: sino a lo que pueda convenirse entre todos los agentes decidientes (entre lo que les pidan sus respectivos cuerpos), que serán todos (hechos ciudadanos y no meros animales de concreto género fáunico). Y no porque unos cuantos pergeñen un ideal más o menos arcádico, fruto de sus delirios o, en el mejor de los casos, de sus buenas intenciones, sino porque tal les pide su circunstancia fisiológica, por así decir. Convivir es bueno, válganos la frase y entiéndase bien, porque se quiere, porque permite la ejecución del placer en la forma que cada cual tenga a bien concederse y porque faculta más y mejor placer. Por tanto, es el formal criterio de convivencia ${ }^{95}$ el que pasa a decidir el contenido material de la construcción política. No porque sea el más simpático o el más racional en sí o el más ajustado a trascendencias ignotas, o la síntesis de una tradición que procede dialécticamente, sino por algo mucho más terrestre y mucho más sencillo y mucho más complicado: porque lo pide el cuerpo que quiere y razona.

En era de crisis económica, que viene a ser sobre todo crisis política, se tiende a huir por vías salvíficas de escape, aunque sean meloso atrezo, que a menudo

91 O mejor, en terminología epicúrea, un placer catastemático continuo, el estado de placer, digamos: un solletico generale sostenuto, por seguir, dándole la vuelta, con la enuncianción usada anteriormente.

92 Bios theoretikós, cuya fijación como summum bonum depende de la prescripción natural que canoniza y hace del cuerpo humano un objeto de destino (en el sentido fuerte de la idea): es para la eudaimonia por esencia, por condición natural.

93 Y mutable, claro, pues la fórmula de la forma es lo que designe el placer, y tal, muta, como sabemos y hemos visto.

94 Salvamos, por enésima vez, la base de todo: seguir viviendo para seguir obteniendo placer y en modo que pueda seguirse obteniendo cuanto se quiera y pueda.

95 Que será acordada y placentera o no será. 
fugan hacia los límites de lo inteligente. Y en ese magma pseudosoteriológico, tan caliente que aniquila, se acaban fundiendo en el desastre las rutas de huida. Parece que la salvación de la cosa fluctúa hoy entre la contemporánea opción excluyente de un individualismo infantil y un neocomunitarismo adolescente en la que el humano pierde sus atributos: el individuo lo es (individuo) por naturaleza, y por artificio es comunitario porque así lo quiere, porque así se lo pide el cuerpo. Un entorno que pretende instituirse, que ordena la convivencia y que se instituye según voluntad, poder y razón no puede obviar tal obviedad: que cada humano, cada vida humana es indivisible y lo es en su querer y en su querer posible. Pero el rango de posibilidades de ese querer viene, a un tiempo, constreñido y aumentado por la poderosa causa que son los otros quereres: una política que no entiende eso y que no procede en función de esa obviedad, más que política es y será guerra. Rebanar lo individual (que es cuerpo que desea y goza, no lo olvidemos, en este entorno epicúreo-hobbesiano) arrojándolo a la fosa común o sacrificar lo común al capricho despiadado de cada cual no es política, es y será guerra. Y necedad, si se quiere convivir y no contravivir.

El común apoyo y la soledad enriquecen: el individualismo comunitario. Pensamos que en cierto modo relevante también ahí nos lleva la enseñanza de Epicuro. Sin fantasmas.

Y la política deberá fluir por la margen que el acuerdo de placeres, de anhelos delimite.

La discusión política contemporánea se olvida de un viejísimo proyecto vital que parece adecuado para convivir y que no apela a la desnuda razón, sino al cuerpo que la usa y la contiene. Y cuyo criterio no es abstracto, ni necesita de coartada ideal, sino bien concreto, aunque igualmente fugaz: abiertamente jugar el placer, aunar el deseo, conducir ${ }^{96}$ la convivencia de los cuerpos felizmente díscolos de los humanos. Así leemos la propuesta epicúrea. Seguimos pudiendo aprender de los viejos clási$\cos$.

El eterno problema de los fundamentos de la política y su racionalidad, la eterna cuestión sobre los principios de la acción y el fin del humano ${ }^{97}$, secularmente y generalmente fijos y pre-establecidos, ligados a racionalidad autosuficiente, naturaleza intencional, trascendencia perfecta o mandato divino adquirió y adquiere un nuevo color con Epicuro y con Hobbes. Y hoy se revela como algo más evanescente y a un tiempo más sencillo:

En un universo mecánico y material, donde además no hay instancia superior conocida que ordene (¿qué puede ordenar una ley desconocida e incognoscible?), ni voluntad ni canon (ni, por tanto, fin), es el querer de todos los humanos, constreñido por las leyes de causa-efecto detectables que lo rigen, el que rige el destino del hombre, que ahora ya no está pre-escrito, ni es fatal. En sus manos, en su cuerpo queda inventar su vida, en el sentido más desolador y consolador de la idea. En una confluencia tal de anhelos sólo cabe el pacto para ordenar el fluir y contener el desborde. Y eso es la política. Lo demás es guerra.

Gobernar, en el sentido de la raíz griega, ahora rescatado por la popularidad de la governance.

97 Recordemos el expresivo pasaje del Leviathan: "For there is no such Finis ultimus, (utmost ayme,) nor Summum Bonum, (greatest Good,) as is spoken of in the Books of the old Morall Philosophers" (T. Hobbes, op. cit., p. 75). 